\title{
(AS)SIMETRIAS DE GÉNERO: SUCESSOS E BARREIRAS EM DISCURSOS PROFISSIONAIS
}

Carla Alexandra F. da Silva ${ }^{\mathrm{I}}$

Gil MachadoII

Sara Isabel Magalhães ${ }^{I I I}$

I Universidade do Porto (U.Porto), Porto, Portugal; carlaalexandrasilva5@gmail.com

II Universidade do Porto (U.Porto), Porto, Portugal; gilmachado5@gmail.com

III Universidade do Porto (U.Porto), Porto, Portugal; saramagalhaes@fpce.up.pt

\section{Resumo}

As escolhas profissionais e oportunidades de vida são influenciadas pelo género criando expectativas sociais distintas. $\mathrm{O}$ mesmo acontece frente às visões de sucesso, reforçando assimetrias sociais e profissionais entre mulheres e homens. Para compreender como as conceções de género se traduzem nas perceções de sucesso profissional, conduzimos nove entrevistas a residentes e trabalhadoras/es em Portugal. Os discursos extraídos por análise temática organizam-se em três temas interligados pelo conceito de assimetrias de género. Conclui-se que as práticas discursivas veiculam inflexibilidade nas construções do género que penalizam o desenvolvimento da carreira da mulher pela sobrecarga das responsabilidades domésticas e pela desvalorização da feminilidade em percursos profissionais.

RELAÇÕES DE GÉNERO • DIFERENÇA DE SEXO • SUCESSO • DESIGUALDADE SOCIAL

\section{GENDER (A)SYMMETRIES: SUCCESS AND BARRIERS IN PROFESSIONAL DISCOURSES}

\begin{abstract}
Gender influences career choices and life opportunities, creating different social expectations. The same is true of visions of success, reinforcing social and professional asymmetries between women and men. To understand how conceptions of gender translate into perceptions of professional success, we conducted nine interviews, in Portugal, with residents and workers. The discourses extracted by thematic analysis were organized into three themes interconnected by the concept of gender asymmetries. We have concluded that discursive practices communicate inflexibility in gender constructions that penalize women's career development due to the overload of domestic responsibilities and the devaluation of femininity in professional paths.
\end{abstract}

GENDER RELATIONS • SEX DIFFERENCE • SUCCESS • SOCIAL INEQUALITY 


\section{(LAS)SIMETRÍAS DE GÉNERO: ÉXITOS Y BARRERAS EN LOS DISCURSOS PROFESIONALES}

\section{Resumen}

Las opciones profesionales y las oportunidades de vida están influenciadas por el género, creando expectativas sociales distintas. Lo mismo puede decirse de las visiones de éxito, reforzando las asimetrías sociales y profesionales entre mujeres y hombres. Para entender cómo las concepciones de género se traducen en percepciones de éxito profesional, realizamos nueve entrevistas con residentes y trabajadores en Portugal. Los discursos extraídos por el análisis temático se organizan en tres temas interconectados por el concepto de asimetrías de género. Se concluye que las prácticas discursivas transmiten inflexibilidad en las construcciones de género que penalizan el desarrollo de las carreras de las mujeres debido a la sobrecarga de responsabilidades domésticas y la desvalorización de la feminidad en los trayectos profesionales.

RELACIONES DE GÉNERO • DIFERENCIA DE SEXO • ÉXITO • DESIGUALDAD SOCIAL

\section{(A)SYMÉTRIES DE GENRE : RÉUSSITES ET OBSTACLES DANS DES DISCOURS PROFESSIONNELS}

\section{Résumé}

Les choix professionnels et les opportunités de vie sont influencés par le genre, créant différentes attentes sociales. Il en va de même pour les visions de la réussite qui renforcent les asymétries sociales et professionnelles entre hommes et femmes. Pour comprendre comment les conceptions de genre se traduisent en termes de perception de la réussite professionnelle, nous avons mené neuf entretiens auprès de résidents et de travailleurs des deux sexes au Portugal. Les discours recueillis par analyse thématique ont été organisés en trois thèmes interconnectés par le concept d'asymétries de genre. La conclusion est que les pratiques discursives révèlent une inflexibilité en matière de construction de genre qui pénalise l'évolution de carrière des femmes en raison de la surcharge des responsabilités domestiques qui leur incombent et de la dévalorisation de leurs parcours professionnels.

RELATIONS DE GENRE • DIFFÉRENCE DE SEXE • SUCCÈS • INÉGALITÉ SOCIALE 
GÉNERO ENQUANTO CONCEITO NÃO É UMA PROPRIEDADE INDIVIDUAL, MAS UMA característica das situações sociais: tanto como base e consequência das interações sociais e, também, como um meio de legitimação de uma das divisões mais fundamentais da sociedade (feminino e masculino) (West \& Zimmerman, 1987).

O género é "feito" nos mais variados contex tos e nas mais pequenas coisas, tornando os domínios das nossas vidas genderizados. Por exemplo, pessoas de géneros diferentes trabalham em diferentes tipos de atividades profissionais (Lorber, 1994). Trabalhos considerados de maior ou menor estatuto moldam as experiências de homens e mulheres, as quais produzem diferentes emoções, consciências e competências - formas de ser que denominamos femininas ou masculinas (Lorber, 1994). O que se tem observado é que essas formas de "ser" são mais penalizantes para as mulheres do que para os homens, já que há uma associação natural das mulheres ao feminino e dos homens ao masculino. No contexto português, em particular, as mulheres continuam a assumir a maior parte do trabalho não remunerado, sendo Portugal o quarto país da Organização para a Cooperação e o Desenvolvimento Económico (OCDE) onde as mulheres fazem mais trabalho não pago (superior a quatro horas por dia), tais como as tarefas domésticas e cuidar de familiares. No entanto, a participação no mercado de trabalho, em contexto nacional, é das mais igualitárias, o que reforça a sobrecarga das mulheres, que se dividem entre as tarefas profissionais e as responsabilidades domésticas. As desigualdades de género persistem em todas as áreas da vida social e económica (OCDE, 2017).

Essas e outras assimetrias integram os processos da construção social do género (Lorber, 1994). Por isso, clarificar a distinção entre sexo e género é essencial para evitar a colagem dos dois conceitos, que fazem das identidades, papéis, comportamentos e divisões sociais ontologia, perpetuando a naturalização dos processos de produção de sentido sobre o sexo (Amâncio, 2003). Nesse sentido, o presente artigo procura compreender como as conceções de género se traduzem nas perceções de sucesso profissional de homens e mulheres. Ou, mais especificamente, como mulheres e homens definem o sucesso profissional e como as conceções de sucesso se relacionam com o conceito de género.

Este estudo assume o género como construção social, produzido pelo discurso que constrói as masculinidades e feminilidades, mantendo as relações sociais e de poder, bem como as ideologias dominantes (Nogueira, 2003). Rejeitam-se o essencialismo e os pressupostos de que as categorias da realidade são divisões reais (Burr, 1995). Procura-se, por isso, aceder a significados pessoais, contextualizados numa história e cultura, tentando explorar a multiplicidade de discursos construídos (Braun \& Clarke, 2013; Burr, 1995).

\section{Género como construção de diferenças}

O conceito de género, desde a sua génese, tem sido confundido com o conceito de sexo. No entanto, o primeiro refere-se e insere-se na cultura, enquanto o segundo pertence ao domínio da biologia (Nogueira \& Saavedra, 2007). Dessa forma, o género concretiza a construção social e diferencia mulheres de homens (Santos, 2007), sendo socialmente esperado que eles adotem comportamentos diferentes e assumam papéis sociais distintos (Nogueira \& Saavedra, 2007). E, embora a investigação sobre as diferenças de género pareça vir a concluir que as diferenças existentes entre feminino e masculino não são assim tão evidentes e que a diversidade vai além dessa dicotomia simplista entre homens e mulheres, a crença de que eles são opostos persiste.

A reificação dessa narrativa bipolar das diferenças tem vindo a justificar a construção rígida das categorias sociais do género geradoras de expectativas sociais atribuídas aos indivíduos, por vezes mesmo 
antes do seu nascimento, tais como escolhas profissionais, oportunidades de vida e até características de personalidade. Todas essas conceptualizações partem do imaginário social familiar, tendo um peso considerável nas escolhas pessoais (Santos, 2007), ao longo da vida. A perspetiva dos papéis sociais advoga que há uma construção social do género, sendo esses papéis crenças bastante consensuais acerca dos atributos das mulheres e dos homens. Mais ainda, esses atributos são encarados como normativos e as tendências comportamentais socialmente aceitas e desejáveis para cada sexo (Eagly \& Karau, 2002).

Essa organização tende a estereotipar e criar expectativas sobre as reações e comportamentos dos/as outros/as e sobre os nossos próprios comportamentos (Santos, 2007). Referências estereotipadas sobre o masculino e o feminino representam ambos os grupos como internamente homogéneos e diferenciados entre si (Barberá, 2004). Por exemplo, a visão tradicional de género atribui ao homem um estatuto mais elevado, sendo encarado como principal fonte de rendimento da família, enquanto a mulher é relegada para o papel de cuidadora. Tendencialmente, um desvio a essas normas leva a que as pessoas sejam vistas de forma menos favorável (Gaunt, 2013) e, potencialmente, alvos de discriminação.

Também nos comportamentos sociais se dicotomizam as interpretações do género. De acordo com os estereótipos sociais, as mulheres são passivas, cooperativas e expressivas, enquanto os homens são agressivos, competitivos e instrumentais (Barberá, 2004). Por seu lado, o comportamento de ajuda das mulheres é mais orientado para as necessidades dos/as outros/as, possuindo um maior sentido de responsabilidade e empatia, como prestar apoio emocional ou aconselhamento sobre problemas pessoais (Eagly \& Crowley, 1986). Para o género masculino, esse tipo de comportamento assume a forma de conduta heroica, ajudando outras/os e correndo riscos em relação a si próprio (Eagly \& Crowley, 1986). Nesse sentido, podemos concluir que a maioria das interações entre os sexos decorre de um contexto estruturalmente desvantajoso para as mulheres, mantendo a categoria sexo como uma diferença saliente socialmente construída (Nogueira, 2003).

\section{Desigualdades e discriminação}

O género é encarado como constructo social que constrói um sistema de significados, organiza as interações e governa o acesso ao poder e recursos (Nogueira, 2003). Esse facto pode levar à criação de estereótipos de género que geram desigualdades e discriminação, tendencialmente, em relação às mulheres.

Essas desigualdades estão presentes desde muito cedo: as/os adolescentes são segregadas/os pelos papéis de género. Estudos concluem que a maioria dos/as adolescentes apresenta uma visão dicotómica dos papéis sociais que lhes estão acessíveis: os adolescentes do sexo masculino acreditam que o dever do homem como marido é ter trabalho, manter financeiramente a sua família, bem como reger-se por valores como responsabilidade, educação e fidelidade; as adolescentes, por sua vez, confinam-se ao dever de cuidar do foro privado/doméstico e a valores como afetuosidade/carinho e compreensão (Hernández, 2006). Constata-se ainda que as construções e práticas discursivas encaram a mulher como um ser frágil e sujeita a corresponder aos padrões impostos, como a contínua aprendizagem da sexualidade e a idealização da aparência (Magalhães, 2011). Essas formulações sociais restringem os papéis possíveis e evitam a emancipação das mulheres (Magalhães, 2011).

Essa desigualdade surge claramente no mundo laboral. Com a entrada das mulheres no mercado de trabalho e as revoltas sociais para a igualdade social, esperava-se que a discriminação sexual da mulher desaparecesse, pois mulheres e homens estariam unidos na concretização de um modelo societal comum (Nogueira, 2006). Contudo, essa igualdade está longe de ser uma realidade. Parece haver um "teto de vidro" que representa as barreiras invisíveis que dificultam o acesso das mulheres a cargos de liderança (Nogueira, 2004), mesmo quando estas estão mais bem preparadas (Nogueira, 2006). Verifica-se assim que as poucas mulheres que ocupam altos cargos hierárquicos encontram-se frequentemente em atividades que se caracterizam como tipicamente femininas (Nogueira, 2006) e, que quando os atingem, são descritas a partir de atributos masculinos, independentemente da área de trabalho (García-Retamero \& López-Zafra, 2006). Depreende-se assim que as mulheres enfrentam 
mais barreiras no seu percurso laboral do que os homens. Contudo, nos seus discursos, as mulheres têm posições contraditórias no que concerne à discriminação. Apesar de negarem a discriminação, mencionam que precisam lutar mais para alcançar os mesmos objetivos dos homens e afirmam ter circunstâncias de vida diferentes (Nogueira, 2006).

Em suma, é importante desmistificar a premissa que assume que as mulheres são mais parecidas com as próprias mulheres do que com os homens, simplesmente porque são mulheres (Nogueira \& Saavedra, 2007). As práticas discursivas vigentes continuam a representar as mulheres de uma forma mais rudimentar e com pouca visibilidade. Essa dicotomia de género mantém-se apesar do reconhecimento da variabilidade interindividual e intragrupal do género e da comprovação empírica das semelhanças entre mulheres e homens, sendo difícil ultrapassar a crença de que homens e mulheres representam polos de uma só dimensão (Nogueira \& Saavedra, 2007).

\section{Conceção do sucesso profissional}

$\mathrm{Na}$ literatura, o conceito de sucesso aparece relacionado com o nível da aquisição de competências sociais/relacionais (Machado et al., 2008), ou ligado à vertente académica (Costa \& Faria, 2015). O sucesso associado à carreira define-se como o acumular de resultados positivos profissionais e psicológicos que advêm das experiências laborais, relacionando-se com os resultados desejáveis, avaliados com base nas próprias expectativas (Arthur et al., 2005).

A avaliação do sucesso depende muito dos referenciais utilizados nesse julgamento. Quando a avaliação tem por base uma fonte externa, seus determinantes são objetivos e os critérios visíveis. A esta vertente do conceito chamamos de sucesso objetivo na carreira, tendo como marcadores o salário, as distinções curriculares ou a formação obtida (Delgado et al., 2014; Judge et al., 1995). Por outro lado, quando a avaliação é pessoal, denominamos o sucesso de subjetivo, considerando a perceção da própria pessoa sobre as suas realizações, a partir de critérios pessoais (Delgado et al., 2014). Como marcadores desse tipo de sucesso contam-se as aspirações pessoais, os sentimentos de realização ou a satisfação com a carreira (Abele \& Spurk, 2009; Judge et al., 1995).

Neste artigo há um foco na vertente subjetiva do sucesso. Por isso, com o intuito de circunscrever o conceito, restringir-nos-emos à Teoria Sociocognitiva do Desenvolvimento de Carreira (TDSC) (Lent et al., 1994), que permite entender o sucesso com base no desenvolvimento de interesses e escolhas profissionais, considerando um número alargado de influências no desenvolvimento de carreira. A TDSC é um modelo abrangente e integrado de teorias já existentes, cujo objetivo é explicar as dinâmicas/mecanismos por meio dos quais: se desenvolvem interesses académicos e de carreira; se fazem escolhas de carreira; e se alcança sucesso (nas realizações/desempenhos) (Lent et al., 1994).

A abordagem sociocognitiva centra a sua análise na compreensão das decisões das pessoas, a partir do seu próprio ponto de vista e liberdade de decisão (Bandura, 2006). As decisões das pessoas traduzem-se em três mecanismos sociocognitivos principais: autoeficácia, ${ }^{1}$ expectativas ${ }^{2}$ e objetivos. ${ }^{3}$ Apesar da centralidade dos três mecanismos, a TDSC reconhece que as escolhas estão sujeitas às mais variadas influências. Nesse sentido, o referencial é utilizado como uma via para analisar o modo como esses fatores podem influenciar o desenvolvimento de carreira.

1 A autoeficácia refere-se à perceção das pessoas sobre a sua capacidade para agir e alcançar certos objetivos ou desempenhos. Considera-se que as perceções de autoeficácia ajudam na escolha de atividades e ambientes, bem como no esforço despendido e reação aos obstáculos encontrados. É um mecanismo dinâmico e complexo, interagindo com outros domínios da ação humana, como comportamentos e contextos.

2 As expectativas de certos resultados caracterizam-se pelas consequências esperadas de determinadas ações. Estas podem assumir várias formas, como uma recompensa salarial (física) ou a aprovação social de uma decisão (social), podendo influenciar as escolhas na carreira (Bandura, 1986).

3 Os objetivos jogam um papel importante na regulação do comportamento. A sua definição leva a que as pessoas se incentivem de forma intrínseca, alcançando sucesso mesmo sem reforço externo. Partindo de critérios pessoais, estes atuam através da representação dos resultados a atingir e da avaliação da pessoa sobre as ações. 
Dentro desse quadro conceptual sociocognitivo, distinguem-se, ainda, alguns modelos básicos, que permitem considerar a ação dos mecanismos centrais e de outros fatores influenciadores de forma integrada (Lent et al., 1994). O modelo de escolha ocupacional, relacionado com o momento de entrada no mundo profissional, afirma que as pessoas tendem a se inclinar mais para determinado tipo de atividades, interagindo mais com outras pessoas semelhantes a si próprias/os (Lent \& Brown, 1996). Contudo, as escolhas profissionais nem sempre refletem os interesses pessoais de cada um/a, revelando a existência de condições que potenciam ou restringem a liberdade de ação/escolha (Lent \& Brown, 1996). Por um lado, essas influências funcionam como barreiras, desencorajando a pessoa a seguir determinados interesses e investir no domínio profissional, dificultando o desenvolvimento da carreira (Swanson \& Woitke, 1997). O conceito de barreira é útil para compreender as desigualdades relativas às mulheres, associadas ao significado social dos papéis de género. Se as condições do meio impedem esforços para atingir certos resultados, é menos provável que haja investimento nessas ações (Lent et al., 2000). Por outro lado, alguns fatores incentivam a prossecução de determinada escolha, mesmo em confronto com barreiras. São fatores de suporte, como a educação livre de estereótipos ou reais possibilidades de ascensão na carreira profissional, que facilitam a tradução dos objetivos em ações concretas para os alcançar (Lent et al., 2000).

O modelo do desempenho na carreira, ligado ao desenrolar da própria experiência de trabalho, conta dois aspetos principais: o nível do desempenho nas tarefas profissionais; e a persistência perante os obstáculos ao desenvolvimento da atividade profissional ou trajetória de carreira (Lent \& Brown, 1996). O nível dos desempenhos depende da perceção de eficácia e das expectativas em relação às tarefas ou a uma carreira específica. No entanto, esses desempenhos dependem do contexto sociocultural em que decorrem, incentivando ou servindo como barreira à sua realização (Lent \& Brown, 1996). Mais uma vez, os papéis de género ilustram bem esse enquadramento. A mulher tende a se comportar de forma feminina, conduzindo a uma maior valorização do papel familiar e, consequentemente, a uma maior divisão do investimento entre a família e o desenvolvimento profissional (Ngo et al., 2014). Como fatores de suporte, atenuantes das barreiras, contam-se a eficácia de coping, relativo às perceções que se têm sobre as barreiras e respetiva capacidade para ultrapassá-las com sucesso (Lent et al., 2000), ou uma maior divisão das tarefas domésticas, o que pode incentivar um maior investimento e expectativas de sucesso no desenvolvimento de carreira.

Todos os aspetos associados ao desenvolvimento de carreira dependem da escolha individual, sujeita a constrangimentos contextuais.

Os comportamentos adaptativos são vistos como atitudes usadas pelas pessoas para ajudar a direcionar o seu desenvolvimento de carreira, em circunstâncias consideradas normais ou sob condições diferentes das quotidianas, incluindo comportamentos pró-ativos ou reativos (antecipar alguma situação ou reagir a um acontecimento) (Lent \& Brown, 2013). Esse conceito é particularmente útil para discutir estratégias utilizadas por trabalhadoras/es na gestão da sua carreira ou para lidar com os desafios a ela associados (Lent \& Brown, 2013). Na presente investigação, o conceito tem como função permitir à pessoa destacar quais as vertentes percecionadas como mais importantes no desenvolvimento de carreira (e.g. procurar promoções ou gerir conflitos trabalho-família).

\section{Género nas conceções de sucesso profissional}

O sucesso na carreira é habitualmente percebido através do reconhecimento alcançado no desempenho das tarefas profissionais. No entanto, a gestão da carreira mostra que nem sempre é possível isolar o sucesso na carreira das outras esferas da vida (Costa, 2010).

As diferenças de género na forma como se define sucesso podem ajudar a explicar as realizações distintas de homens e mulheres na nossa sociedade, dado o impacto significativo nas escolhas tanto na vida pessoal como na profissional (Dyke \& Murphy, 2006), a influência sobre as conceções do que é ser bem-sucedido (Lee et al., 2006) e a avaliação individual do sucesso de homens ou mulheres (Ngo et al., 2014). O modo como definimos o sucesso consegue influenciar não apenas as escolhas educacionais, 
do emprego e do envolvimento no trabalho, mas também as relações interpessoais, os compromissos familiares e até a satisfação com a vida (Dyke \& Murphy, 2006). Para os homens, tradicionalmente, o sucesso na carreira refere-se às realizações conseguidas no âmbito meramente profissional, enquanto para as mulheres pode significar a obtenção do equilíbrio entre os diferentes papéis e a saliência de várias identidades que ocorrem ao longo da sua vida (Lee et al., 2006). Ter flexibilidade para combinar as exigências do lar e do trabalho é um fator importante, particularmente para as mulheres, ao passo que para os homens o foco primordial é a carreira, esperando estes que a vida familiar e comunitária surja do sucesso obtido no âmbito profissional (Cornelius \& Skinner, 2008). Os homens valorizam mais o sucesso em termos materiais/financeiros, salientando a importância da independência e de deixar uma contribuição significativa na organização (Dyke \& Murphy, 2006). A principal marca de sucesso para as mulheres é o equilíbrio entre a vida profissional e a vida familiar, sendo o desenvolvimento do potencial profissional considerado bem-sucedido se for associado ao estabelecimento de relações interpessoais no trabalho (Dyke \& Murphy, 2006).

Persiste, ainda, uma visão tradicional dos papéis de género. Constata-se que altos níveis de masculinidade se relacionam com uma avaliação mais positiva do ambiente de trabalho e da carreira, já que se orientam mais para as tarefas e investem mais na progressão profissional (Ngo et al., 2014). Já pessoas que assumem o papel com características associadas à feminilidade apresentam níveis inferiores de satisfação com a carreira, procurando mais o estabelecimento de relações e a gestão positiva da vida familiar com a vida profissional (Ngo et al., 2014).

As visões de sucesso e género constroem-se, portanto, a partir da noção do ser como socialmente construído, contingente a um sistema histórico, social e político do qual não pode ser retirado (Nogueira et al., 2005). Essas construções revelam relações de poder assimétricas, em que habitualmente as características masculinas e dominantes são mais valorizadas. Para objetivamente promover oportunidades igualitárias para homens e mulheres, necessitamos compreender melhor o que o sucesso significa para ambos (Dyke \& Murphy, 2006).

\section{Metodologia}

\section{Participantes}

Participaram neste estudo nove pessoas - quatro mulheres e cinco homens. Todas vivem e trabalham em Portugal e têm idades entre 26 e 52 anos (Quadro 1).

\section{QUADRO 1}

DADOS SOCIODEMOGRÁFICOS DOS/AS PARTICIPANTES

\begin{tabular}{|cccccc|}
\hline Pessoas & Idade & Sexo & Estado civil & Filhos/as & Cargo profissional \\
G.C. & 30 & Mulher & União de facto & Não & Coordenadora de departamento \\
G.M. & 33 & Homem & União de facto & Sim & Responsável de secção laboratorial \\
L.M. & 26 & Mulher & Solteira & Não & Investigadora académica \\
L.P. & 27 & Homem & Casado & Não & Operacional no ramo das forças policiais \\
M.R. & 52 & Mulher & Casada & Sim & Professora efetiva \\
P.A. & 46 & Mulher & Casada & Sim & Técnica assistente de saúde oral \\
P.I. & 32 & Homem & União de facto & Não & Coordenador de departamento \\
R.N. & 33 & Homem & União de facto & Não & Coordenador de organização de saúde pública \\
S.F. & 43 & Homem & Casado & Sim & Gestor de topo \\
\hline
\end{tabular}

Fonte: Dados da pesquisa. 


\section{Procedimento}

Os/As participantes foram recrutadas/os com base num perfil profissional definido pela equipa de investigação e que cruzava experiência de liderança e perceções pessoais de sucesso. A maioria das/ os participantes que se voluntariaram para o estudo pertencia à rede alargada de contactos da equipa. Após o estabelecimento do primeiro contacto, foi formalizado o pedido de colaboração, explicando em que se baseava o estudo. As entrevistas realizaram-se em locais distintos, sempre marcadas de acordo com a disponibilidade das/os entrevistadas/os, assegurando a confidencialidade e anonimato das/os participantes. A condução das entrevistas decorreu com a privacidade necessária, garantindo assim a sua qualidade. Foi pedido a cada um/a dos/as participantes a devida autorização para a gravação de seus áudios. Posteriormente, foi realizada a sua transcrição verbatim. A duração média das entrevistas foi de 45 minutos. O fim do recrutamento aconteceu devido à saturação teórica (Fontanella et al., 2008).

\section{Instrumentos}

Uma vez que se procura compreender a experiência de eventos e de que modo as pessoas dão significado ao mundo, adotou-se uma metodologia qualitativa (Willig, 2010). Foram escolhidas duas técnicas de recolha de dados: a entrevista semiestruturada e a organização de cartões. A primeira possibilita o acesso em profundidade às experiências e aos pontos de vista das pessoas (Turner, 2010). A condução das entrevistas foi orientada, com flexibilidade, por um guião elaborado com base na literatura previamente revista, contendo três eixos principais auxiliares da construção da narrativa: género (e.g. Para si o que é ser homem/mulher?); percurso de carreira (e.g. Quais os fatores que mais promoveram o seu percurso profissional?); e perceções do domínio profissional/pessoal (e.g. Acha que existe relação entre o domínio profissional e o domínio pessoal?)

Já a segunda técnica - recolha de dados - consistiu na organização de cartões, compostos por seis afirmações adaptadas da lista de comportamentos adaptativos (Lent \& Brown, 2013), presente no enquadramento teórico: ${ }^{4}$ promoção/ascensão de carreira; aumentos salariais; formação complementar; traçar planos de carreira; conciliação família-trabalho; e dimensão identitária/profissional. A leitura e organização dos cartões foi pedida na parte final da entrevista, solicitando-se a organização por ordem de importância, segundo três perspetivas distintas: perspetiva da própria pessoa; importância atribuída ao género oposto; e importância atribuída ao próprio género.

\section{Análise de dados}

Recorreu-se à análise temática de discurso para realizar a análise dos dados recolhidos por meio das entrevistas, seguindo as etapas propostas por Braun e Clarke (2006, 2013). Esse procedimento permite identificar, analisar e narrar padrões, organizando e descrevendo o conjunto de dados em detalhe (Braun \& Clarke, 2006, 2013). A abordagem analítica foi predominantemente dedutiva, já que existiu um envolvimento prévio com a literatura sobre a temática (Braun \& Clarke, 2006, 2013). A escolha do procedimento de análise traduz o posicionamento epistemológico deste trabalho. A grelha de leitura tem presente uma perspetiva construcionista social, não essencialista (Braun \& Clarke, 2006), escolhida pela importância colocada nas interações e linguagem, por meio da consideração dos significados pessoais como produzidos e reproduzidos socialmente (Burr, 1995).

Relativamente à modalidade de organização dos cartões, depois de registadas todas as disposições concretizadas pelos/as entrevistados/as, foi analisada a tendência de ordem de importância das três ordens solicitadas. Essa técnica serviu como suporte complementar à análise e discussão dos dados, sustentando-os e enriquecendo-os.

4 Dois cartões foram reformulados, numa ótica conceptual (gerir conflitos trabalho-família e gerir aspetos da identidade pessoal), uma vez que o sentido original poderia potencialmente induzir as respostas, remetendo para algo que provoca dificuldades. Passou-se a denominar os cartões como conciliação família-trabalho e dimensão identitária/pessoal, tendo os restantes mantido o seu sentido original, em termos conceptuais. 


\section{Apresentação e discussão de resultados}

Cumpridos os procedimentos da análise de dados, iremos sistematizar os nossos resultados, constituídos por três temas - a base do sucesso; linearidade sexo/género; e barreiras profissionais de género - e respetivos subtemas (Figura 1). O organizador central da análise - (as)simetrias de género - é destacado já que o caráter assimétrico e binário desse conceito marca os discursos sobre as vivências das pessoas entrevistadas.

Figura 1

MAPA TEMÁTICO

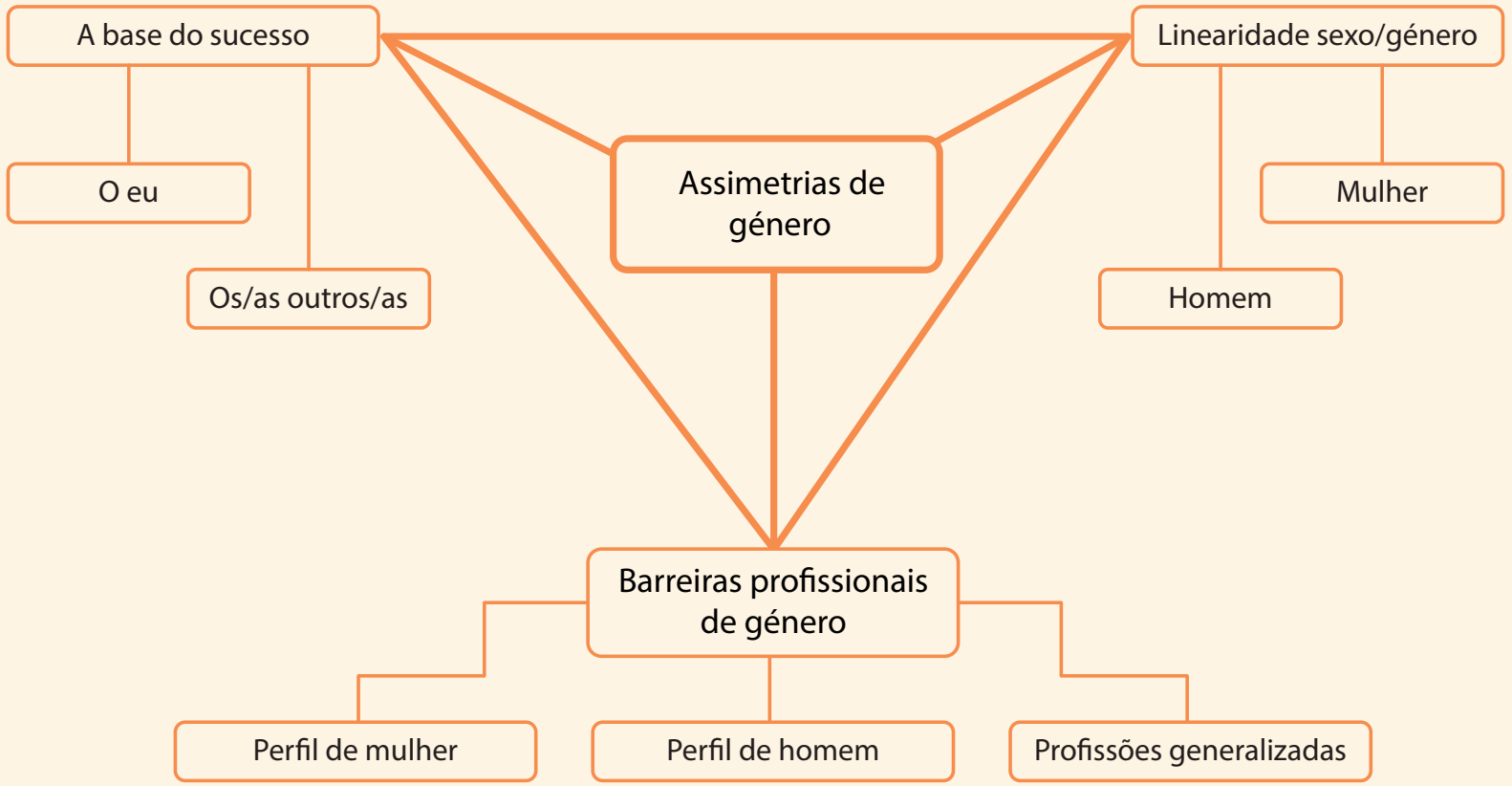

Fonte: Elaboração das autoras e do autor.

\section{A base do sucesso}

Tal como acontece com as questões de género, é impossível isolar o sucesso profissional dos demais domínios da vida (Costa, 2010); esses domínios encontram-se entrecruzados, distinguindo o que representa ter sucesso para mulheres e homens (Lee et al., 2006). Os discursos dos/as participantes revelam essas diferenças de género em relação ao sucesso, contudo, são apenas visíveis quando falam na terceira pessoa, ou seja, a existência de assimetrias de género é verbalizada somente quando se referem ao percurso de outros/as. Dessa forma, surgem dois subtemas que espelham essas visões distintas: o eu e os/as outros/as.

$\mathrm{O}$ eu

Em geral, assume-se um conceito de sucesso profissional que privilegia, para as mulheres, a conciliação entre a vida profissional e a familiar e, para os homens, uma valorização da carreira e só depois da vida familiar, como consequência do sucesso profissional (Cornelius \& Skinner, 2008).

No entanto, as pessoas entrevistadas apresentam uma visão pessoal de sucesso que demonstra uma menor presença de estereótipos e conceções assimétricas de género. Referem que a família se encontra na base do sucesso, concebendo uma visão comum para homens e mulheres que se opõem à perspetiva de que são as mulheres a privilegiarem a conciliação. Também a tendência da organização dos cartões segundo a perspetiva do eu coloca a conciliação família-trabalho em primeiro lugar. As/os entrevistadas/os definem uma espécie de hierarquia na relação profissional-pessoal, em que a família aparece como pedra angular que possibilita o investimento profissional: 
Eu acho que a base de tudo é de facto a nossa vida e a nossa familia, os nossos amigos e esta parte da conciliação familia-trabalho é o que nos dá também... um foco no nosso trabalho, porque de facto temos uma boa base sustentada. (R.N.).

Salientam, também, uma relação recíproca entre o campo laboral e familiar, em que uma boa estrutura familiar é requisito fundamental para o sucesso profissional. Por outro lado, as dificuldades profissionais são mitigadas pela família, enquanto o contexto profissional não possui força para cumprir a função inversa:

... para mim o maior sucesso está na familia e depois vem a profissão, porque na hora da profissão correr mal nós temos um apoio que é a familia... . e se na familia correr mal, não é a profissão que nos apoia, portanto eu acho que o primeiro sucesso é a familia. (M.R.).

A satisfação provém da plena conciliação entre a família e o trabalho, ao alcançar um equilíbrio entre vida pessoal e trabalho (Sturges, 2008), tanto para os homens como para as mulheres entrevistados/as:

... a parte familiar é muito, é muito importante, porque se tivermos só sucesso a nivel empresarial e depois do lado da familia, não tivermos muito interessados ou só focados no trabalho e depois, por exemplo, não acompanhamos a evolução de um filho, da sua educação e isso tudo. (S.F.).

\section{Os/as outros/as}

Em oposição à visão do eu, as pessoas entrevistadas atribuem aos outros homens e às outras mulheres uma visão que demarca a existência de diferenças e assimetrias de género relativamente ao sucesso (Nogueira \& Saavedra, 2007).

Os homens valorizam mais as realizações pessoais obtidas do investimento profissional e que lhes conferem autonomia e satisfação material/financeira (Dyke \& Murphy, 2006): "Porque acho que são muito mais individualistas, pensam muito mais neles primeiro ... primeiro pensa nele . . tentar conciliar a família ali já num plano mais abaixo" (P.A.).

Essa conceção do homem que o desvincula da importância da conciliação profissional e dos deveres familiares tende a fazer-se em oposição aos encargos, tradicionalmente domésticos, da mulher (Schnurr et al., 2020). Segundo estes discursos, o homem procura o contexto familiar como ponto de apoio para as dificuldades pontuais que emergem da sua vida profissional: ". . . eu acho que [o homem] põe o trabalho primeiro e depois é que se surge algum problema eles, . . é 'ai a minha familia, é ali que eu vou procurar o apoio'...” (G.M.). A tendência de organização dos cartões para o homem, em geral, sublinha os discursos anteriores, ao colocar a conciliação família-trabalho num segundo plano, priorizando as questões identitárias/pessoais e a promoção/ascensão na carreira.

Essa visão das/os entrevistadas/os para as/os outras/os integra a conciliação como marcador feminino de sucesso (Dyke \& Murphy, 2006; Emslie \& Hunt, 2009; Ngo et al., 2014). Parece ser partilhada a noção de que as mulheres possuem características "femininas" que provêm do seu sexo biológico, estando mais "adaptadas" ao papel doméstico no âmbito familiar dada a orientação para o contacto interpessoal. Segundo essa lógica, é esperado que mulheres bem-sucedidas invistam tanto na sua atividade profissional como no trabalho familiar e doméstico: “. . para uma mulher ter sucesso esta questão da conciliação família-trabalho ainda seria mais importante”(R.N.). No mesmo sentido, a tendência de organização dos cartões para a mulher, em geral, prioriza a conciliação família-trabalho.

Contudo, a real concretização dessa conciliação não é simples e direta, porque o alcance de um equilíbrio no investimento entre os dois contextos pode acarretar um grande "desgaste" (R.N.). A conciliação revela-se assim fundamental, dado que uma maior dedicação das mulheres ao trabalho pode impedir o cumprimento das "obrigações" familiares (França, 2012): "[Por ficar a trabalhar até mais tarde] . . Perdi muito do crescimento das minhas filhas, sem dúvida"(P.A.). 
Esse discurso mostra uma visão do eu que corrobora o constructo de sucesso associado à conciliação família-trabalho (G.C.; R.N.; S.F.). Simultaneamente, refuta a noção de que as mulheres são, por excelência, quem mais facilmente encontra uma harmonia entre o trabalho e a vida pessoal (Emslie $\&$ Hunt, 2009). No entanto, essas conceções penalizam as mulheres, uma vez que as forçam à adesão ao estereótipo da feminilidade. Ou seja, mulheres trabalhadoras vivem com a culpa de estar a faltar aos deveres familiares e, por norma, acumulam uma sobrecarga de trabalho doméstico como um dever assumido (Amâncio, 2017; Matias et al., 2011). Por outro lado, quando sacrificam as responsabilidades familiares pela dedicação ao trabalho, falham nas suas "obrigações" relativamente a um modelo de maternidade intensivo dentro do qual a prioridade é a educação dos/as filhos/as (César et al., 2018).

\section{Linearidade sexo/género}

O género enquanto constructo social e culturalmente construído estabelece crenças bastante consensuais acerca dos atributos e comportamentos associados a cada um dos sexos (Nogueira, 2003). As narrativas das/os participantes traçam uma linearidade entre os dois constructos (sexo e género), definindo dois polos de uma única dimensão, negando o conceito de género como um contínuo. Nesse sentido, ser-se homem apenas significa ser-se "puramente masculino" e ser-se mulher implica ser-se "puramente feminina. No tema da linearidade sexo/género dicotomizam-se dois subtemas apresentados a seguir: homem e mulher.

\section{Homem}

Essa linearidade atribui estatutos diferentes à mulher e ao homem, sendo conferido um estatuto de superioridade ao homem, enquanto fonte de rendimento familiar (Gaunt, 2013), com uma relação específica relativa à vertente financeira e salarial. Ser masculino pressupõe, segundo esses discursos, uma remuneração suficiente para suportar a família: “. . . eles pensam muito mais rápido nos aumentos salariais do que eu, como vejo as mulheres, pensariam, mas porque também aos homens lhes está ligado muito a função do 'ganha pão' da família” (L.M.). De acordo com a organização dos cartões, as/os entrevistadas/os referem que o homem, em geral, valoriza mais na sua vida os aspetos de identidade pessoal e da carreira profissional. Apenas em segundo plano, surgem as questões relacionadas com a conciliação do trabalho-família.

Esses discursos destacam a visão tradicional de que é suposto o homem ganhar mais do que a mulher (Schnurr et al., 2020). Mais ainda, excluem a mulher de qualquer estatuto de sustento familiar (superior ou inferior). A linearidade está, também, presente nos discursos acerca do papel do homem na parentalidade e enquanto cuidador. Essa genderização penaliza e inferioriza o homem quanto ao seu papel mais "familiar", sendo considerado uma espécie de assistente com uma função de entretenimento $\mathrm{da}(\mathrm{s})$ criança(s), dado que a sua competência de cuidador não é comparável à da mulher (Sunderland, 2000): "Por muito que os homens agora tentem ajudar, não é a mesma coisa de todo"(P.A.).

\section{Mulher}

A conceção essencialista do sexo e género remete-nos para o estatuto da mulher enquanto cuidadora (Gaunt, 2013) como uma determinação biológica dentro da qual ser mulher implica o dever de cuidar do foro privado/doméstico, bem como da família e filhos/as (Hernández, 2006).

Os discursos sobre as características atribuídas ao homem excluem a mulher do papel de trabalhadora, embora todas as participantes mulheres trabalhem a tempo inteiro. Apesar de a mulher ter uma presença considerável no mercado de trabalho (Coimbra \& Fontaine, 2010), com profissões e exigências similares às do homem, não se observa uma divisão igualitária das tarefas familiares (Matias et al., 2011). Assume-se um dever e competência natural da mulher para amar os/as filhos/as, o marido, ser carinhosa e responsável (Hernández, 2006), algo que se incompatibiliza com as conceções do homem e masculino, exploradas anteriormente: 
Esta é simples, a mulher dá sempre muito mais valor aos filhos . . E depois, por exemplo, há aquela parte... da gravidez, a mulher é sempre quem vai para as aulas de parto, para o médico, tudo isso. É quem amamenta e depois é quem dá educação ao filho, quem acompanha muito mais a criança ou as crianças. (P.I.).

Os pressupostos de género prescrevem a responsabilidade pela lida doméstica à mulher, sendo esta a "dona de casa”. As tarefas domésticas estão largamente feminizadas, já que são as mulheres que asseguram regularmente a preparação das refeições, limpeza da casa e cuidado da roupa (Perista, 2002): "... eu tenderia logo a falar na mulher, no seu papel de mulher como ... mãe, dona de casa, isso tudo" (P.A.). Na mesma lógica, a organização tendencial dos cartões pelos/as entrevistados/as aponta que a mulher, em geral, valoriza fortemente os aspetos da conciliação trabalho-família e da identidade pessoal, em detrimento de todas as questões relacionadas com a carreira profissional.

Essas desigualdades tornam linear a associação sexo/género, surgindo ainda de forma legítima e aceitável no que respeita à distribuição de poder e responsabilidades em relação tanto ao trabalho como à vida familiar (Nogueira, 2003).

\section{Barreiras profissionais de género}

Nem sempre as escolhas profissionais refletem os interesses pessoais de cada um/a. As conceções de género introduzem um sentido linear não apenas nas escolhas ocupacionais, mas também no modo de agir nessas escolhas, criando perfis específicos para cada pessoa/género. Os discursos das pessoas entrevistadas ressaltam duas visões opostas e mutuamente exclusivas sobre a forma de atuar no campo laboral. Esses perfis de género sublinham maioritariamente as qualidades do perfil masculino, enquanto atribuem características depreciativas ao perfil feminino. Além disso, as próprias profissões são divididas numa lógica estereotipada, criando os "trabalhos de homens" e os "trabalhos de mulheres". Nesse sentido, dentro do espetro do tema barreiras profissionais de género, surgem três subtemas: perfil da mulher, perfil do homem e profissões genderizadas.

\section{Perfil da mulher}

As/os participantes constroem perfis estereotipados que englobam comportamentos prescritos ao género, dentro do contexto profissional. A esfera do feminino é essencialmente definida através da vertente afetiva e relacional, denominada usualmente de expressividade (Ferreira et al., 2013). Essa componente emocional caracteriza as mulheres como sendo mais conflituosas e sensíveis (Ferreira et al., 2013), já que tendem a exteriorizar mais os seus estados de espírito, sendo encaradas pelos discursos como geradoras de conflitos e deteriorando o ambiente profissional: "O homem está à procura da resolução/solução, a mulher está à procura da complicação"(G.C.).

Destacam-se a sensibilidade emocional das mulheres e a consequente exteriorização das preocupações afetivas no espaço profissional:

... as mulheres transparecem mais o que sentem do que os homens e quando as coisas não estão bem a nivel pessoal, a nivel profissional, eu vejo com as que trabalho, consigo entender quando as coisas não estão bem a nivel pessoal. (G.M.).

Segundo estes discursos, as mulheres são, também, vistas como tendo dificuldades na sua afirmação no trabalho e pela ausência de sentido de autoridade:

... imporem-se mesmo, ... chegar ali com uma postura forte, não é de "ai deixa estar tudo bem e tal", não, isso nunca vai resultar. Portanto, a mulher que chega a uma situação qualquer e... são molinhas, não sei. (L.P.).

Por último, sublinha-se uma competência que surge exclusivamente associada ao "sentido feminino", a organização: “. . . as mulheres são mais metódicas, mais organizadas, se calhar também pela obrigação, ou digamos pela essência ... porque está inerente à mulher” (P.I.). 
Essas características, baseadas numa construção estereotipada, acabam por funcionar como barreira profissional para as mulheres. Os atributos da feminilidade, também presentes nesses discursos, são inconsistentes com os requisitos tidos como necessários para singrar em várias posições organizacionais importantes (Heilman \& Eagly, 2008). Mais ainda, as mulheres que atingem cargos mais elevados são, normalmente, masculinizadas (García-Retamero \& López-Zafra, 2006), demonstrando a incompatibilidade entre as expectativas de um bom desempenho profissional e as características femininas (Heilman \& Eagly, 2008).

\section{Perfil do homem}

A imagem do homem, traçada nos discursos das/os entrevistadas/os, mantém as conceções opostas às da mulher. Desse modo, a hegemonia do masculino é definida por uma vertente de ação, denominada de instrumentalidade, sobressaindo aspetos como personalidade forte, segurança, competência, capacidade de tomar decisões sem ajuda, capacidade de chefia e independência (Ferreira et al., 2013). O homem é descrito como um potenciador da harmonia no ambiente profissional, acrescentando amizade e sinceridade a esse contex to: “. . o próprio ambiente entre homens, ... maior parte é sempre muito mais humilde e sincero” (G.C.).

Além disso, o homem é considerado mais prático e menos problemático na resolução das questões laborais: “. . . os homens são muito menos complicados a trabalhar do que as mulheres, eu acho isso desde sempre” (P.A.).

Por último, destaca-se um maior impacto da presença da masculinidade, já que o homem é percebido como uma maior fonte de autoridade e tendo uma personalidade mais forte: "Imposição. Não só, presença. A presença de um homem, neste momento, a nivel social é mais forte do que uma mulher" (L.P.).

As características do homem estão explicitamente mais associadas à liderança. Dessa forma, as barreiras existentes nos percursos profissionais parecem estar muito mais ativas para as mulheres do que para os homens (Nogueira, 2006), pelo simples facto de os homens agirem de forma masculina. Essa visão do masculino como competente traz consigo um duplo dilema para as mulheres: as que adotam características masculinas, conseguindo ter sucesso na execução de tarefas e responsabilidades profissionais, transgridem as prescrições normativas de género (Eagly \& Karau, 2002); as que adotam características mais "naturais" podem ver impedido o seu desenvolvimento profissional, com uma avaliação menos positiva da sua competência e profissionalismo (Ferreira et al., 2013). Por conseguinte, o perfil masculino delineado inferioriza o homem quanto ao seu papel familiar e doméstico.

Esses discursos dão origem a perfis de género estanques e assimétricos, dificultando a construção de visões híbridas sobre as características pessoais (Nogueira \& Saavedra, 2007).

\section{Profissões genderizadas}

De acordo com os/as participantes, os contextos profissionais parecem "genderizar-se". Os homens tenderiam a escolher profissões mais condizentes com a masculinidade e as mulheres mais ligadas às relações e pessoas (Ramaci et al., 2017). O mundo parece estar organizado segundo essa lógica binária com uma estrita compatibilidade entre género e profissão, sendo sexo e género encarados como conceitos sinónimos, inatos e imutáveis, restringindo as opções ocupacionais para cada sexo/género (Coimbra \& Fontaine, 2010).

\section{... há um estereótipo, no sentido que o serviço social é para mulheres e eu ainda hoje vivo com esse} preconceito das pessoas... "ai serviço social? Isso é um curso para mulheres". (R.N.).

A genderização das profissões, segundo os discursos, tende a funcionar como barreira na ascensão da carreira para as mulheres, ou seja, existe uma espécie de "teto de vidro", pelo facto de as barreiras se demonstrarem invisíveis (Wirth, 2001; Nogueira, 2004). Essa noção do "teto de vidro" torna clara a ligação entre barreiras profissionais, características do perfil da mulher e a noção doméstica da mulher, acabando por inferiorizar o seu estatuto na relação com posições laborais de topo associadas a maiores salários e mais responsabilidades nas organizações (Figueiredo \& Botelho, 2013). 
A mulher "simplesmente" tem de trabalhar mais para atingir os mesmos objetivos dos homens (Nogueira, 2006), lutar contra as expectativas sociais (Eagly \& Karau, 2002), correndo sempre o risco de não ser propriamente mulher (masculinização do sucesso) (García-Retamero \& López-Zafra, 2006): “... os homens por norma têm mais facilidade em chegar ao topo ... do que as mulheres que são mais discriminadas"(S.F.).

\section{Considerações finais}

Partindo das teorizações ligadas ao género e sucesso profissional, recolheram-se histórias de homens e mulheres que contam os seus discursos profissionais/pessoais. As assimetrias de género organizam as experiências das/os entrevistadas/os em todos os contextos de vida, impregnando-os de conceções dicotómicas e rígidas. Os binarismos de género estão espelhados na estrutura temática deste trabalho e, consequentemente, nas seguintes considerações.

Os discursos analisados opõem duas visões sobre o que constitui a base para o sucesso. A visão pessoal, do $e u$, demonstra uma simetria de género quanto à definição do sucesso. A visão dos/as outros/as reproduz as assimetrias tradicionais, distinguindo o que é sucesso para o homem e o que é sucesso para a mulher. A visão do eu estabelece uma relação hierárquica na qual a família é uma condição obrigatória para o investimento no trabalho, sendo que uma definição completa de sucesso contempla um equilíbrio entre vida profissional e pessoal (Sturges, 2008). Na visão dos/as outros/as, os papéis sociais do género e as assimetrias marcam a construção dos sucessos de homens e mulheres, representando um regresso à perspetiva tradicional patente também no exercício da organização de cartões. A tendência de organização, na perspetiva pessoal, mostra a conciliação família-trabalho como prioritária no desenvolvimento de carreira, sem distinção de géneros. Já a organização para a mulher atribui clara prioridade à conciliação, enquanto para o homem o foco muda para as questões de carreira, numa vertente mais individualista. Essa associação do homem ao trabalho e ao retorno material daí obtido (Dyke \& Murphy, 2006) e da mulher às responsabilidades domésticas femininas penaliza as mulheres em duplo sentido: ou são sobrecarregadas com os deveres da família, ou, caso sacrifiquem as responsabilidades familiares, falham nas suas “obrigações” (Amâncio, 2017; França, 2012; César et al., 2018).

O sexo é linearmente associado ao género pelos/as entrevistados/as, desligando o último conceito do seu espetro social. Assim, as mulheres agem de forma feminina e os homens de forma masculina (Eagly \& Karau, 2002), sem possíveis cruzamentos ou continuidades.

O exercício de organização dos cartões reforça essas perspetivas, frisando a importância prioritária de as mulheres balançarem as responsabilidades familiares com as do trabalho, enquadrando o desenvolvimento de carreira em segundo plano para o feminino. A linear associação sexo/género penaliza novamente as mulheres, porque são elas que asseguram a maioria das tarefas domésticas, enquanto participam, de modo semelhante aos homens, no mercado de trabalho (Perista, 2002; Coimbra \& Fontaine, 2010). Essas assimetrias geram desigualdades na distribuição de poder e responsabilidades, ainda legitimadas dentro do panorama social vigente (Nogueira, 2003).

O género influencia também as escolhas ocupacionais, funcionando principalmente como barreira para as mulheres, devido ao significado social e à ligação a papéis específicos (Nogueira \& Saavedra, 2007), criando perfis profissionais de comportamentos masculinos e femininos. O perfil da mulher condiz com a feminilidade, no qual se destacam características relacionais e emocionais que são depreciativas. Nesse cenário, há uma incompatibilidade entre um bom desempenho profissional e as características femininas (Heilman \& Eagly, 2008), acabando as normas prescritivas do género por funcionarem como barreira à progressão de carreira (Nogueira, 2004). Por sua vez, o perfil do homem mantém a superioridade masculina, dada a capacidade de harmonizar o ambiente profissional com amizade e pragmatismo, retirando os fatores problemáticos destacados no perfil da mulher. Mais uma vez, essas conceções castigam a mulher e o feminino. As mulheres mais masculinas transgridem as 
normas de género (Eagly \& Karau, 2002), ao passo que as mais femininas veem colocadas mais barreiras ao seu desenvolvimento profissional, dada a associação menos positiva da feminilidade com o perfil de competência e profissionalismo (Ferreira et al., 2013). As convenções do género também classificam dicotomicamente os percursos académicos e as profissões, convergindo com os perfis profissionais anteriores. Assim, os percursos estereotípicos masculinos destinam-se aos homens, vincando-se características como autoridade e empreendedorismo. Os percursos estereotípicos femininos encaixam com as mulheres, pois sublinham a orientação para as relações e as pessoas (Ramaci et al., 2017). A genderização das escolhas ocupacionais opera como um teto de vid ro na progressão laboral das mulheres, ao inferiorizar as características femininas e dificultar o acesso a posições de chefia, que se associam a maiores salários e responsabilidades (Figueiredo \& Botelho, 2013; Wirth, 2001). A chegada a esse estatuto implica uma luta contra as expectativas sociais, podendo conduzir à perda da feminilidade no caminho para o sucesso (Eagly \& Karau, 2002; García-Retamero \& López-Zafra, 2006).

$\mathrm{O}$ processo de investigação permitiu debater o género numa lógica conceptual, dando simultaneamente acesso a histórias de vida que se fazem a partir e contra o próprio género. A necessidade de categorização mostra como o género, influenciador dos sucessos, invade precoce e inevitavelmente os nossos discursos, forçando os seus binarismos a essas práticas discursivas. As genderizações rígidas dos papéis sociais começam desde a socialização precoce e são mantidas pelas atitudes/comportamentos veiculados durante o exercício da parentalidade (OCDE, 2017).

Em suma, as práticas discursivas desses/as participantes veiculam a inflexibilidade nas construções do género, mesmo integrando nas suas vidas práticas diárias que poderiam servir para mudar visões e problematizar as lógicas dominantes (Nentwich, 2008). O género é feito mantendo as normas predefinidas e os estados ontológicos, que reproduzem a sua naturalidade, hegemonia e a lógica hierárquica/binária da sua construção (Nentwich, 2008). Homens e mulheres, femininos e masculinos são ainda construções arrastadas para a simplicidade da visão unidimensional (Nogueira \& Saavedra, 2007), servindo como amarras discursivas da sua problematização. Por isso, dificultam conceções mais focadas nas pessoas e menos em categorias ilusórias. Sentimos que as reflexões sobre sucesso e género deste trabalho contribuíram para a sua desconstrução, oferecendo mais um passo no longo caminho para uma sociedade mais fluída, igualitária e livre.

\section{Referências}

Abele, A. E., \& Spurk, D. (2009). The longitudinal impact of self-efficacy and career goals on objetive and subjective success. Journal of Vocational Behavior, 74, 53-62. https://doi.org/10.1016/ j.jvb.2008.10.005

Amâncio, L. (2003). O género no discurso das ciências sociais. Análise Social, 38(168), 687-714.

Amâncio, L. (2017). Assimetria simbólica: Breve história de um conceito. In J. M. Oliveira, \& L. Amâncio (Orgs.), Género e sexualidades: Interseções e tangentes (pp. 17-36). Centro de Investigação e de Intervenção Social (CIS IUL). https://gensexinter.tumblr.com/

Arthur, M. B., Khapova, S. N., \& Wilderom, C. P. M. (2005). Career success in a boundaryless career world. Journal of Organizational Behavior, 26, 177-202. https://doi.org/10.1002/job.290

Bandura, A. (1986). Social foundations of thought and action: A social cognitive theory. Prentice Hall.

Bandura, A. (2006). Toward a psychology of human agency. Perspectives on Psychological Science, 1, 164-180. https://doi.org/10.1111/j.1745-6916.2006.00011.x

Barberá, E. H. (2004). Perspectiva socio-cognitiva: Estereótipos y esquemas de género. In E. Barberá, \& I. M. Benlloch (Coords.), Psicología y género (pp. 55-80). Pearson Educación, S. A.

Braun, V., \& Clarke, V. (2006). Using thematic analysis in psychology. Qualitative Research in Psychology, 3, 77-101. http://dx.doi.org/10.1191/1478088706qp063oa 
Braun, V., \& Clarke, V. (2013). Successful qualitative research: A practical guide for beginners. Sage.

Burr, V. (1995). An introduction to social constructionism. Routledge.

César, F., Oliveira, A., \& Fontaine, A. (2018). Modelos sociais de maternidade difundidos em páginas e grupos do Facebook em Portugal. Análise Psicológica, 36(1), 47-59. http://dx.doi.org/10.14417/ap.1333

Coimbra, S., \& Fontaine, A. M. (2010). Será que sou capaz?: Estudo diferencial de auto-eficácia com alunos do nono ano. Revista Brasileira de Orientação Profissional, 11(1), 5-22.

Cornelius, N., \& Skinner, D. (2008). The careers of senior men and women - A capabilities theory perspective. British Journal of Management, 19, 141-149. https://doi.org/10.1111/j.1467-8551.2008.00579.x

Costa, A., \& Faria, L. (2015). The impact of emotional intelligence on academic achievement: A longitudinal study in Portuguese. Learning and Individual Differences, 37, 38-47. https://doi.org/10.1016/j. lindif.2014.11.011

Costa, L. V. (2010). A relação entre a percepção de sucesso na carreira e o comprometimento organizacional: Um estudo entre professores de universidades privadas selecionadas da Grande São Paulo [Tese de doutorado]. Faculdade de Administração, Economia e Contabilidade, Universidade de São Paulo, São Paulo, Brasil.

Delgado, A., Saletti-Cuesta L., López-Fernández,L.A., Toro-Cárdenas, S., \& Castillo L.J.D. (2014).Professional success and gender in family medicine: Design of scales and examination of gender differences in subjective and objective success among family physicians. Evaluation \& Health Professions, 39(1), 87-99. https://doi.org/10.1177/0163278714543686

Dyke, L. S., \& Murphy, S. A. (2006). How we define success: A qualitative study of what matters most to women and men. Sex Roles, 55, 357-371.

Eagly, H., \& Crowley, M. (1986). Gender and helping behavior: A meta-analytic review of social psychology literature. Psychological Bulletin, 100, 283-308. https://doi.org/10.1037/0033-2909.100.3.283

Eagly, H., \& Karau, S. J. (2002). Role congruity theory of prejudice toward female leaders. Psychological Review, 109(3), 573-598. https://doi.org/10.1037/0033-295X.109.3.573

Emslie, C., \& Hunt, K. (2009). "Live to work" or "work to live"? A qualitative study of gender and work-life balance among men and women in mid-life. Gender, Work and Organization, 16(1), 151-172. https://doi.org/10.1111/j.1468-0432.2008.00434.x

Ferreira, S. I., Saavedra, L., Taveira, M. C., \& Araújo, A. M. (2013). Escolhas e planeamento de carreira: A tirania dos discursos tradicionais. Revista Brasileira de Orientação Profissional, 14(2), 165-175.

Figueiredo, M. C., \& Botelho, M. C. (2013). Decomposition of the gender wage gap in Portugal, 1998-2007: The evidence of gender discrimination. Portuguese Journal of Social Science, 12(3), 287-315. https://doi. org/10.1386/pjss.12.3.287_1

Fontanella, B. J., Ricas, J., \& Turato, E. R. (2008). Amostragem por saturação em pesquisas qualitativas em saúde: Contribuições teóricas. Cadernos de Saúde Pública, 24(1), 17-27. https://doi.org/10.1590/ S0102-311X2008000100003

França, T. (2012). Women and labor market: Work family conflict and career self-management. Revista Pensamento \& Realidade, 27(4), 51-70.

García-Retamero, R., \& López-Zafra, E. (2006). Congruencia de rol de género y liderazgo: El papel de las atribuciones causales sobre el éxito y el fracasso. Revista Latinoamericana de Psicología, 38(2), 245-257.

Gaunt, R. (2013). Breadwinning moms, caregiving dads: Double standard in social judgments of gender norm violators. Journal of Family Issues, 24(1) 3-24. https://doi.org/10.1177/0192513X12438686

Heilman, M. E., \& Eagly, A. H. (2008). Gender stereotypes are alive, well, and busy producing workplace discrimination. Industrial and Organizational Psychology, 1, 393-398. https://doi.org/10.1111/j.17549434.2008.00072.x

Hernández, O. M. (2006). Adolescentes y representaciones de género sobre la familia y sus membros en Ciudad Victoria Tamaulipas. Revista Internacional de Ciencias Sociales y Humanidades, 16(2), 9-30. 
Judge, T. A., Cable, D. M., Boudreau,J. W., \& BretzJr, R.D. (1995). An empirical investigation of the predictors of executive career success.Personnel Psychology, 48(3),485-519.https://doi.org/10.1111/j.17446570.1995. tb01767.x

Lee, M. D., Lirio, P., Karakas, F., MacDermid, S. M., Buck, M. L., \& Kossek, E. E. (2006). Exploring career and personal outcomes and the meaning of career success among part-time professionals in organizations. In R. J. Burke (Ed.), Research companion to work hours and work addiction (pp. 284-309). Edward Elgar.

Lent, R. W., \& Brown, S. D. (1996). Social cognitive approach to career development: An overview. The Career Development 2uarterly, 44, 310-321. https://doi.org/10.1002/j.2161-0045.1996.tb00448.x

Lent, R. W., \& Brown, S. D. (2013). Social cognitive model of career self-management: Toward a unifying view of adaptive career behavior across the life span. Journal of Counseling Psychology, 60(4), 557-568. https://doi.org/10.1037/a0033446

Lent, R. W., Brown, S. D., \& Hackett, G. (1994). Toward a unifying social cognitive theory of career and academic interest, choice, and performance [Monograph]. Journal of Vocational Behavior, 45, 79-122. https://doi.org/10.1006/jvbe.1994.1027

Lent, R. W., Brown, S. D., \& Hackett, G. (2000). Contextual supports and barriers to career choice: A social cognitive analysis. Journal of Counseling Psychology, 47(1), 36-49. https://doi.org/10.1037/00220167.47.1.36

Lorber, J. (1994). "Night to his day": The social construction of gender. In J. Lorber (Ed.), Paradoxes or gender (pp. 13-36). Yale University Press.

Machado, P., Veríssimo, M., Torres, N., Peceguina, I., Santos, A. J., \& Rolão, T. (2008). Relações entre o conhecimento das emoções, as competências académicas, as competências sociais e a aceitação entre pares. Análise Psicológica, 26(3), 463-478.

Magalhães, S. I. (2011). Como ser uma Ragazza. Discursos de sexualidade numa revista para raparigas adolescentes [Tese de doutorado em Psicologia]. Escola de Psicologia da Universidade do Minho, Braga, Portugal.

Matias, M., Andrade, C., \& Fontaine, A. M. (2011). Diferenças de género no conflito trabalho-família: Um estudo com famílias portuguesas de duplo-emprego com filhos em idade pré-escolar. Psicologia, 25(1), 9-32.

Nentwich, J. C. (2008). New fathers and mothers as gender troublemakers? Exploring discursive constructions of heterosexual parenthood and their subversive potential. Feminism \& Psychology, 18(2), 207-230. https://oi.org/10.1177/0959353507088591

Ngo, H. Y., Foley, S., Ji, M. S., \& Loi, R. (2014). Linking gender role orientation to subjective career success: The mediating role of psychological capital. Journal of Career Assessment, 22(2), 290-303. https://doi. org/10.1177/1069072713493984

Nogueira, C. (2003). "Ter" ou "fazer" o género: O dilema das opções epistemológicas em psicologia social. Comunicação apresentada no XII Encontro Nacional da ABRAPSO sobre estratégias de intervenção a Psicologia social, Pontifícia Universidade Católica do Rio Grande do Sul, Porto Alegre, Brasil.

Nogueira, C. (2004). As mulheres em posição de poder: Razões para uma cidadania activa. A Comuna: Feminismo e Marxismo, 4, 16-23.

Nogueira, C. (2006). Os discursos das mulheres em posições de poder. Cadernos de Psicologia Social do Trabalho, 9(2), 57-72.

Nogueira, C., Neves, S., \& Barbosa, C. (2005). Fundamentos construcionistas sociais e críticos para o estudo do género. Psicologia: Teoria, Investigação e Prática, 2, 1-15.

Nogueira, C., \& Saavedra, L. (2007). Estereótipos de género: Conhecer para os transformar. Cadernos SACAUSEF, 3, 10-30.

Organização para a Cooperação e o Desenvolvimento Económico (OCDE). (2017). The pursuit of gender equality: An uphill battle. OECD Publishing. http://dx.doi.org/10.1787/9789264281318-en 
Perista, H. (2002). Género e trabalho não pago: Os tempos das mulheres e os tempos dos homens. Análise Social, 37(163), 447-474.

Ramaci, T., Pellerone, M., Ledda, C., Presti, G., Squatrito, V., \& Rapisarda, V. (2017). Gender stereotypes in occupational choice: A cross-sectional study on a group of Italian adolescents. Psychology Research and Behavior Management, 10, 109-117. https://doi.org/10.2147/PRBM.S134132

Santos, J. A. (2007). Igualdade de género em alcance: Considerações para o estabelecimento de novas relações sociais. Revista Eletrônica de Ciências Sociais, 1, 113-129. https://periodicos.uff.br/index.php/csonline/ article/view/17034

Schnurr, S., Zayts, O., Schroeder, A., \& Le Coyte-Hopkins, C. (2020). "It's not acceptable for the husband to stay at home": Taking a discourse analytical approach to capture the gendering of work. Gender, Work and Organization, 27, 414-434. https://doi.org/10.1111/gwao.12408

Sturges, J. (2008). All in a day's work? Carreer self-management and the management of the boundary between work and non-work. Human Resource Management Journal, 18(2), 118-134. https://doi.org/10.1111/ j.1748-8583.2007.00054.x

Sunderland, J. (2000). Baby entertainer, bumbling assistant and line manager: Discourses of fatherhood in parentcraft texts. Discourse \& Society, 11(2), 249-74. https://doi.org/10.1177/0957926500011002006

Swanson, J. L., \& Woitke, M. B. (1997). Theory into practice in career assessment for women: Assessment and interventions regarding perceived career barriers. Journal of Career Assessment, 5(4), 443-462. https://doi.org/10.1177/106907279700500405

Turner, D. W. (2010). Qualitative interview design: A practical guide for novice investigators. The Qualitative Report, 15(3), 754-760. https://nsuworks.nova.edu/tqr/vol15/iss3/19

West, C., \& Zimmerman, D. H. (1987). Doing gender. Gender \& Society, 1(2), 125-51.

Willig, C. (2010). Introducing qualitative research in psychology. Tata McGraw-Hill.

Wirth, L. (2001). Breaking through the glass ceiling: Women in management. International Labour Office.

\section{Nota sobre autoria}

As autoras e o autor participaram igualmente na elaboração e revisão do artigo.

\section{Disponibilidade de dados}

O protocolo de consentimento informado de recolha de dados não incluía a possibilidade de disponibilização em Open Access pelo que a autoria reserva o direito de pré-aprovar a disponibilização dos materiais a quem os solicite revendo o enquadramento do pedido nos fins para os quais obteve consentimento.

\section{Como citar este artigo}

Silva, C. A. F. da, Machado, G., \& Magalhães, S. I. (2021). (As)simetrias de género: Sucessos e barreiras em discursos profissionais. Cadernos de Pesquisa, 51, Artigo e07980. https://doi. org $/ 10.1590 / 198053147980$ 